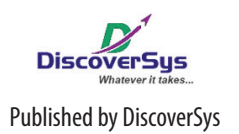

Published by DiscoverSys

\section{Antenatal care behavior as a risk factor of nutritional anemia among pregnant women at South Denpasar II Public Health Centre, 2012}

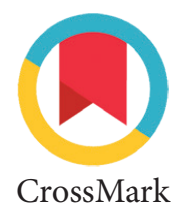

Made Dwi Hendrayani, ${ }^{1,4^{*}}$ Anak Agung Sagung Sawitri, ${ }^{1,2}$ I Nyoman Mangku Karmaya ${ }^{1,3}$

\section{ABSTRACT}

The South Denpasar II Public Health Centre has the highest reported nutritional anemia among pregnant women $(57,4 \%)$ in the year 2011-2012. Nutritional anemia increased the risk of maternal and perinatal mortality, prematurity and low birth weight. This case control study aimed to identify the relationship between antenatal care (ANC) behaviour and nutritional anemia. The study involved 69 cases and 69 controls which taken from pregnant women records April to August 2012 by using a quota sampling. Cases were those with $\mathrm{Hb}$ Sahli levels $<11 \mathrm{gr} / \mathrm{dl}$, whereas those with $\mathrm{Hb}$ Sahli levels $\geq 11$ were used as controls. Demographic characteristics, gestational age, parity, IUD use and ANC patterns were obtained by structured interviews and observations. ANC patterns which was evaluated from frequency and time of ANC and Fe tablets consumption were categorised as sufficient and insufficient. Data were analysed using univariate, bivariate (crude
OR) and logistic regression for adjusted OR. Most women were aged 20-35 and had a low level of education, with gestational age $>1$ st trimester, a parity of $1-3$, and time window between births $<2$ years. Gestational age >1st trimester had 5.17 greater risk of nutritional anemia (95\% Cl: 1.66-16.06). Insufficient ANC behaviour increased risk of nutritional anemia as many as 23.29 (95\%Cl: $7.49-72.33)$ and 9.85 for insufficient Fe tablets consumption (95\%Cl: 3.27-29.68). Most of these women consumed less than $<30$ Fe tablets in the last month. Age, time between births, parity, family income, level of education, nutritional status and history of IUD use were proven not as risk factors. An early approach to newly couples, sekaa teruna teruni and senior high school students is needed to be targeted in regard to information of ANC. A more intensive surveillance is also needed to monitor Fe tablets consumption.

\title{
Perilaku pemeriksaan antenatal sebagai faktor risiko anemia gizi ibu hamil di Puskesmas II Denpasar Selatan tahun 2012
}

\section{ABSTRAK}

${ }^{1}$ Public Health Postgraduate Program Udayana University, ${ }^{2}$ Department of Community and Preventive Medicine, Faculty of Medicine Udayana University, ${ }^{3}$ Anatomy Department, Faculty of Medicine Udayana University, ${ }^{4}$ South Denpasar II Public Health Centre

${ }^{*}$ Correspondence to:

Made Dwi Hendrayani, Public Health Postgraduate Program Udayana University, South Denpasar II Public Health Centre

dwik_ciky12@yahoo.co.id
Puskesmas II Denpasar Selatan tercatat memiliki kasus anemia gizi ibu hamil terbanyak $(57,4 \%)$ pada tahun 2011-2012. Anemia gizi meningkatkan risiko kematian maternal dan perinatal, prematuritas, serta berat badan bayi lahir rendah. Penelitian kasus kontrol ini bertujuan untuk mengetahui perilaku ANC sebagai faktor risiko anemia gizi. Sampel kasus (69 ibu) dan kontrol (69 ibu) diambil dari register ibu hamil periode April-Agustus 2012 dengan teknik kuota. Mereka yang memiliki kadar $\mathrm{Hb}$ Sahli dibawah $<11 \mathrm{gr} / \mathrm{dl}$ ditetapkan sebagai kasus, sedangkan kadar Hb Sahli $\geq 11$ gr/dl digunakan sebagai kontrol. Karakteristik demografi, umur kehamilan, paritas, pemakaian IUD dan pola ANC diperoleh dari wawancara terstruktur dan observasi. Pola ANC dinilai dari frekuensi dan waktu ANC serta jumlah konsumsi tablet Fe dan dikategorikan menjadi memadai dan tidak memadai. Data dianalisa secara univariat, bivariat (crude OR) dan dilanjutkan dengan regresi logistik untuk memperoleh adjusted OR. Sebagian besar ibu berusia 20-35 tahun dan memiliki tingkat pendidikan rendah. Mayoritas dengan umur kehamilan $>$ trimester I, paritas 1-3 dan jarak kelahiran $<2$ tahun. Umur kehamilan >trimester I berisiko 5,17 kali lebih besar terhadap kejadian anemia gizi ( $95 \% \mathrm{Cl}: 1,66-$ 16,06) dibandingkan umur kehamilan trimester I. Frekuensi dan waktu ANC tidak memadai memiliki risiko 23,29 kali lebih besar (95\%Cl: 7,4972,33) dan konsumsi tablet Fe tidak memadai memiliki risiko 9,85 kali lebih besar (95\%Cl: 3,27-29,68). Mayoritas ibu mengkonsumsi tablet Fe sebulan terakhir $<30$ tablet dengan alasan lupa minum. Umur ibu, jarak kelahiran, paritas, pendapatan keluarga, tingkat pendidikan, status gizi dan riwayat pemakaian IUD tidak terbukti meningkatkan risiko anemia. Perlu pendekatan lebih dini terhadap PUS, sekaa teruna teruni dan sekolah menengah keatas di wilayah puskemas untuk memberikan pemahaman tentang ANC. Selain itu, pemantauan kepatuhan konsumsi tablet Fe juga perlu ditingkatkan. 
Kata kunci: ANC, faktor risiko, anemia gizi, kehamilan, Denpasar

Cite This Article: Hendrayani, M.D., Sawitri, A.A.S., Karmaya, I.N.M. 2013. Antenatal care behavior as a risk factor of nutritional anemia among pregnant women at South Denpasar II Public Health Centre, 2012. Public Health and Preventive Medicine Archive 1(1): 74-78. D0l:10.15562/phpma. v1i1.165

\section{PENDAHULUAN}

Berdasarkan laporan World Health Organization (WHO) tahun 2008, prevalensi anemia ibu hamil tahun 1993-2005 di seluruh dunia mencapai 41,8\%. Sementara data dari Health Nutrition and Population Statistics diperoleh prevalensi anemia ibu hamil tahun 2005 di Asia masih cukup tinggi, yaitu berkisar $20 \%$ di Indonesia sampai 56,4\% di Laos. Survei Kesehatan Rumah Tangga tahun 2001 menyebutkan mayoritas penyebab langsung kematian ibu adalah perdarahan (28\%), eklampsia (24\%) dan infeksi (11\%), sedangkan penyebab tidak langsungnya adalah ibu hamil kurang energi kronis (KEK) 37\% dan anemia 40\%.

Beberapa penelitian di Bali menunjukkan prevalensi anemia ibu hamil bervariasi yaitu 21\% (1990); 30\%-50\% (1992-1994) ${ }^{1}$ dan 46,5\% (1997). ${ }^{1}$ Penelitian terakhir tahun 2004, menemukan prevalensi anemia ibu hamil di Bali sebesar 71,1\%. ${ }^{2}$ Data Dinas Kesehatan Provinsi Bali menunjukkan bahwa jumlah kasus anemia tahun 2011 sebanyak 1130 kasus $(9,24 \%)$ dari total ibu hamil. Untuk wilayah Dinas Kesehatan Kota Denpasar, dari 11 Puskesmas yang ada dijumpai kasus anemia tertinggi adalah di Puskesmas II Denpasar Selatan yaitu sebesar 23,3\% (anemia berat 1,67\%, anemia sedang $12,13 \%$ dan anemia ringan 86,19\%). Data komplikasi ibu hamil dijumpai sebesar 33,3\% termasuk di dalamnya adalah perdarahan, sedangkan bayi BBLR yang ditangani yaitu sebesar $2,08 \%$ dan yang dirujuk $1,67 \%$.

Hasil survei awal ${ }^{3}$ di Puskesmas II Denpasar Selatan pada Bulan April-Juni 2011 ditemukan anemia sebanyak $27(57,4 \%)$ dari 47 ibu hamil, dengan faktor yang mungkin berpengaruh yaitu konsumsi tablet Fe, umur kehamilan, keteraturan pemeriksaan ANC dan status gizi kurang. Namun studi pendahuluan tersebut jumlah sampelnya kecil dan penggalian faktor risiko anemia gizi masih dangkal, sehingga diperlukan pendalaman penggalian faktor sebagai risiko terutama yang bisa diintervensi. Penelitian ini bertujuan untuk mengetahui faktor risiko perilaku ANC dalam mempengaruhi anemia gizi pada ibu hamil di wilayah Puskesmas II Denpasar Selatan.

\section{METODE}

Rancangan penelitian ini adalah case control. Kasus dan kontrol adalah ibu hamil yang tercatat di register ibu pada periode April-Agustus 2012 di Puskesmas II Denpasar Selatan. Kasus ditetapkan jika hasil pemeriksaan kadar Hb Sahli dibawah 11 gr/dl dan kontrol jika hasil pemeriksaan kadar $\mathrm{Hb}$ Sahli $\geq 11$ gr/dl. Kriteria inklusi kasus dan kontrol adalah bersedia diwawancara, sedangkan kriteria eksklusinya adalah jika dalam wawancara mengakui menderita malaria, malabsorbsi dan infeksi cacing tambang.

Besar sampel kasus dihitung dengan rumus uji hipotesis untuk $\mathrm{OR}$, dengan perkiraan $\mathrm{OR}=3$, nilai P2 $=0,27 ; \alpha=5 \%$ dan $\beta=85 \%$, dan perbandingan kasus-kontrol 1:1, diperoleh jumlah sampel minimal kasus 69 orang dan kontrol 69 orang. Penentuan sampel secara kuota yaitu kasus dipilih sesuai dengan hasil pemeriksaan kadar $\mathrm{Hb}$ Sahli $<11$ gr/dl yang tercatat di register ibu dan pemeriksaan $\mathrm{Hb}>11$ gr/dl sebagai kontrol sampai dengan jumlah sampel terpenuhi.

Faktor risiko diperoleh dengan melakukan wawancara terstruktur dan observasi kartu ibu. Beberapa variabel yang digali adalah karakteristik ibu hamil, meliputi umur saat hamil, umur kehamilan, paritas, jarak kelahiran, tingkat pendidikan ibu dan pendapatan keluarga. Selain itu juga digali status gizi, riwayat pemakaian IUD dan pola perilaku ANC. Variabel perilaku ANC diukur dengan dua subvariabel pokok yaitu frekuensi dan waktu pemeriksaan kehamilan serta konsumsi tablet Fe. Pendapatan keluarga dianggap cukup bila penghasilan total suami-istri sebesar $\geq 2 \mathrm{x}$ upah minimum regional (UMR) Kota Denpasar. Status gizi dinyatakan baik jika LILA ibu hamil $\geq 23,5 \mathrm{~cm}$. Frekuensi dan waktu pemeriksaan kehamilan dinyatakan memadai jika sesuai standar operasional pelayanan antenatal. ${ }^{4}$ Konsumsi tablet Fe dinyatakan memadai jika jumlah tablet Fe yang dikonsumsi ibu hamil minimal 90 tablet selama kehamilan dan diberikan sejak kontak pertama. ${ }^{4}$

Analisis data dilakukan secara bertahap meliputi analisis univariat, bivariat dan multivariat dengan uji statistik regresi logistik dengan metode backward stepwise (Wald), karena skala data variabel tergantung status anemia gizi ibu hamil adalah nominal dan variabel bebas juga berskala nominal, kemudian data disajikan dalam bentuk matrik, tabel dan narasi. Untuk menghilangkan efek variabel confounding dan untuk mengetahui variabel yang memiliki risiko paling besar dilakukan melalui pemilihan variabel penting yang memiliki $p<0,25$ pada saat dilakukan uji bivariat. Penelitian telah 
dinyatakan laik etik oleh Komisi Etik Penelitian Fakultas Kedokteran Universitas Udayana/Rumah Sakit Umum Pusat Sanglah Denpasar.

\section{HASIL}

Sebagian besar ibu berusia 20-35 tahun dengan tingkat pendidikan yang rendah. Mayoritas ibu memiliki umur kehamilan >trimester I, paritas 1-3 dan jarak kelahiran $<2$ tahun. Detail informasi tersaji pada Tabel 1.

Sebagian besar ibu hamil memeriksakan kehamilannya di puskesmas, namun dengan frekuensi yang tidak memadai. Disamping itu, waktu kedatangan ibu pertama kali mayoritas dilakukan setelah trimester I. Dalam hal konsumsi tablet $\mathrm{Fe}$, sebagian besar juga dijumpai tidak memadai, dimana $55,1 \%$ ibu hamil mengkonsumsi tablet Fe dalam sebulan terakhir $<30$ tablet. Alasan yang paling banyak disebutkan oleh ibu adalah lupa untuk meminumnya. Detail informasi dapat dilihat pada Tabel 2.

Hasil analisis bivariat (crude OR) menunjukkan bahwa umur kehamilan >trimester I memiliki risiko 5,82 kali lebih besar terkena anemia gizi dibandingkan dengan umur kehamilan trimester I, perbedaan risiko antara kedua kelompok tersebut bermakna (OR=5,82; 95\%CI: 2,66-12,74; $\mathrm{p}=0,0001$ ). Ibu hamil dengan pendapatan keluarga $<2$ x UMR memiliki risiko 2,19 kali lebih besar terkena anemia gizi dibandingkan ibu hamil dengan pendapatan keluarga $\geq 2 x$ UMR. Perbedaan antara kedua kelompok tersebut bermakna $(\mathrm{OR}=2,19$; 95\%CI: 1,10-4,39; $\mathrm{p}=0,025)$.

Kelompok ibu dengan LILA $<23,5 \mathrm{~cm}$ memiliki risiko 4,19 kali lebih besar terkena anemia gizi dibandingkan kelompok ibu dengan LILA $\geq 23,5$ $\mathrm{cm}$ dan perbedaan risiko antara kedua kelompok tersebut bermakna $(\mathrm{OR}=4,19$; $95 \% \mathrm{CI}: \quad 1,45-$ $12,10 ; \mathrm{p}=0,005)$. Kelompok yang tidak memadai dalam frekuensi pemeriksaan kehamilan (ANC) memiliki risiko 22,08 kali lebih besar terkena anemia gizi dibandingkan kelompok ibu yang memadai melakukan pemeriksaan kehamilan, dan perbedaan risiko antara kedua kelompok tersebut sangat bermakna (OR=22,08; 95\%CI: 9,01-54,12; $\mathrm{p}=0,0001$ ).

Ibu hamil yang tidak memadai dalam mengkonsumi tablet Fe memiliki risiko 15,53 kali lebih besar terkena anemia gizi dibandingkan ibu hamil yang memadai dalam mengkonsumsi tablet Fe. Hasil ini menunjukkan adanya perbedaan risiko yang bermakna pada kedua kelompok $(\mathrm{OR}=15,53$; 95\%CI: 6,61-36,45; $\mathrm{p}=0,0001$ ).

Pada penelitian ini variabel yang memenuhi syarat untuk dianalisis dengan regresi logistik untuk menghitung adjusted OR adalah umur kehamilan, pendapatan keluarga, status gizi kurang, frekuensi pemeriksaan kehamilan (ANC) dan konsumsi tablet Fe. Variabel ini dianalisis secara bersamasama untuk menentukan model regresi. Hasil akhir analisis didapatkan tiga variabel yang memiliki

\section{Tabel 1 Distribusi karakteristik ibu hamil}

\begin{tabular}{lcc}
\hline Karakteristik & $(\mathbf{n}=\mathbf{1 3 8})$ & Persentase \\
\hline Umur ibu hamil (tahun) & 18 & 13,0 \\
$\quad<20$ atau $>35$ & 120 & 87,0 \\
$20-35$ & & \\
Umur kehamilan & 103 & 74,6 \\
$\quad>$ Trimester I & 35 & 25,4 \\
$\quad$ Trimester I & & \\
Paritas & 66 & 47,8 \\
$\quad 0$ atau $>3$ & 72 & 52,2 \\
$1-3$ & & 53,6 \\
Jarak kelahiran (tahun) & 74 & 46,4 \\
$\quad<2$ & 64 & \\
$\geq 2$ & & 53,6 \\
Tingkat pendidikan ibu & 74 & 46,4 \\
$\quad$ Rendah & 64 & \\
Tinggi & & 51,3 \\
Pendapatan Keluarga & 57 & 58,7 \\
$<2 x$ UMR & 81 & \\
$\geq 2 x$ UMR & & \\
\hline
\end{tabular}


Tabel 2 Distribusi pola perilaku ANC

\begin{tabular}{|c|c|c|}
\hline Karakteristik & $(n=138)$ & Persentase \\
\hline \multicolumn{3}{|l|}{ Tempat layanan } \\
\hline Puskesmas & 96 & 69,6 \\
\hline Rumah sakit pemerintah & 2 & 1,4 \\
\hline Praktek dokter & 3 & 2,2 \\
\hline Praktek bidan & 36 & 26,1 \\
\hline Klinik swasta & 1 & 0,7 \\
\hline \multicolumn{3}{|l|}{ Frekuensi ANC } \\
\hline Tidak memadai & 76 & 55,1 \\
\hline Memadai & 62 & 44,9 \\
\hline \multicolumn{3}{|l|}{ Pertama kali periksa kehamilan } \\
\hline Trimester I & 64 & 46,4 \\
\hline$>$ Trimester I & 74 & 53,6 \\
\hline \multicolumn{3}{|l|}{ Konsumsi Tablet Fe } \\
\hline Tidak memadai & 78 & 56,5 \\
\hline Memadai & 60 & 43,5 \\
\hline \multicolumn{3}{|l|}{ Konsumsi tablet Fe sebulan terakhir } \\
\hline 30 tablet & 62 & 44,9 \\
\hline$<30$ tablet & 76 & 55,1 \\
\hline \multicolumn{3}{|l|}{ Alasan Tablet Fe sisa } \\
\hline Mual/muntah setelah minum tablet $\mathrm{Fe}$ & 7 & 5,1 \\
\hline Lupa minum & 95 & 68,8 \\
\hline Bosan minum & 26 & 18,8 \\
\hline Malas minum & 10 & 7,2 \\
\hline
\end{tabular}

perbedaan risiko yang bermakna terhadap kejadian anemia gizi yaitu variabel umur kehamilan $(\mathrm{OR}=5,17 ; 95 \% \mathrm{CI}: 1,66-16,06 ; \mathrm{p}=0,005)$, frekuensi ANC (OR=23,29; 95\%CI: 7,49-72,33; $\mathrm{p}=0,0001)$ dan konsumsi tablet $\mathrm{Fe}(\mathrm{OR}=9,85$; 95\%CI: 3,2729,$68 ; \mathrm{p}=0,0001$ ).

\section{DISKUSI}

Hasil penelitian menunjukkan bahwa umur kehamilan dan perilaku ANC terbukti sebagai faktor risiko anemia gizi di wilayah Puskesmas II Denpasar Selatan. Umur kehamilan trimester II dan III berisiko 5,17 kali lebih besar untuk anemia kemungkinan karena menjelang trimester tersebut, kebutuhan zat besi meningkat tajam hingga 6,3 $\mathrm{mg} /$ hari, ditambah kebutuhan sel darah merah $150 \mathrm{mg}$ dan conceptus $223 \mathrm{mg} .{ }^{3}$ Dengan meningkatnya kebutuhan $\mathrm{Fe}$ saat hamil apabila tidak diiringi dengan peningkatan masuknya Fe maka akan mudah terjadi anemia gizi. ${ }^{5}$ Dengan keadaan tersebut, kontak pertama ibu hamil dengan tenaga kesehatan yang mempunyai kompetensi untuk mendapatkan pelayanan antenatal, harus dilakukan sedini mungkin pada trimester pertama, sebaiknya sebelum minggu kedelapan. ${ }^{4}$

Dalam studi ini, kontak pertama ibu hamil dijumpai mayoritas $(53,5 \%)$ setelah trimester I dengan frekuensi pemeriksaan yang tidak memadai dan terbukti sebagai faktor risiko anemia $(\mathrm{OR}=23,29)$. Dari hasil wawancara dengan beberapa ibu hamil, peneliti menemukan alasan ibu hamil terlambat memeriksakan kehamilannya karena mereka sibuk bekerja. Hasil penelitian ini sesuai dengan penelusuran faktor risiko anemia di Puskesmas II Denpasar Selatan tahun 2011 bahwa pemeriksaan kehamilan bermakna sebagai faktor risiko anemia dengan $\mathrm{OR}=13,01 .^{6}$

Selain kontak pertama, frekuensi ANC memiliki hubungan timbal balik dengan pengetahuan ibu. Ibu yang memeriksakan kehamilan awal memiliki perhatian dan persepsi yang baik akan pentingnya pemeriksaan yang memadai bagi kesehatan dan janinnya. Sebaliknya, pengetahuan ibu bertambah baik dengan meningkatnya frekuensi pemeriksaan kehamilan, karena pada pelayanan antenatal selain dilakukan pemeriksaan kesehatan juga diberikan konseling kesehatan dan gizi selama kehamilan. ${ }^{4}$ 
Faktor lain yang juga mendukung kejadian anemia adalah jumlah konsumsi tablet Fe yang tidak memadai. Sebagian besar $(55,1 \%)$ ibu hamil mengkonsumsi tablet $\mathrm{Fe}$ dalam sebulan terakhir $<30$ tablet, dengan alasan terbanyak $(68,8 \%)$ adalah lupa untuk meminum tablet Fe tiap harinya. Hasil penelitian ini sesuai dengan penelusuran faktor risiko anemia di wilayah Puskesmas II Denpasar Selatan tahun 2011 bahwa keteraturan konsumsi tablet $\mathrm{Fe}$ bermakna sebagai faktor risiko anemia dengan $\mathrm{OR}=6,3 .{ }^{6}$ Ketidakteraturan ibu hamil dalam mengkonsumsi tablet Fe merupakan salah satu faktor yang dapat meningkatkan risiko terkena anemia.?

Ketiga faktor yang sangat berperan terhadap anemia gizi pada ibu hamil di Puskesmas II Denpasar Selatan tahun 2012, memiliki keterkaitan satu sama lain. Frekuensi pemeriksaan kehamilan dikatakan memadai apabila kontak pertama ibu hamil harus dilakukan sedini mungkin pada trimester pertama, sebaiknya sebelum minggu kedelapan. Hal ini dilakukan sebagai pencegahan terhadap anemia gizi pada ibu hamil, karena pada kehamilan setelah trimester I memiliki risiko lebih besar untuk terkena anemia gizi. Dengan demikian ibu hamil juga dapat sedini mungkin mendapatkan tablet Fe dari petugas kesehatan dan pemantauan terhadap ibu hamil dalam mengkonsumsi tablet Fe dapat dilakukan mulai dari kontak pertama.

Kelemahan dalam penelitian ini adalah pada saat wawancara informasi yang diperoleh mengenai jumlah tablet Fe yang dikonsumsi ibu hamil hanya berdasarkan ingatan tanpa melihat dan menghitung dengan langsung jumlah tablet $\mathrm{Fe}$ yang dikonsumsi.

\section{SIMPULAN}

Variabel-variabel yang secara bermakna paling berperan dapat meningkatkan risiko anemia gizi pada ibu hamil di wilayah Puskesmas II Denpasar
Selatan adalah variabel umur kehamilan dan pola perilaku ANC. Bagi pemegang Program KIA, perlu dilakukan pendekatan lebih dini terhadap PUS, sekaa teruna teruni dan sekolah menengah keatas di wilayah puskemas untuk memberikan pemahaman tentang ANC serta pemantauan kepatuhan konsumsi tablet Fe perlu ditingkatkan.

\section{UCAPAN TERIMA KASIH}

Penulis mengucapkan terima kasih kepada Dinas Kesehatan Kota Denpasar, Puskesmas II Denpasar Selatan serta seluruh responden yang telah membantu pelaksanaan penelitian ini sehingga dapat diselesaikan dengan baik.

\section{DAFTAR PUSTAKA}

1. Bakta, I Made. Hematologi klinik ringkas. Penerbit Buku Kedokteran EGC. Jakarta; 2006.

2. Amiruddin, Ridwan. Studi kasus kontrol faktor biomedis terhadap kejadian anemia ibu hamil di Puskesmas Bantimurung Kabupaten Maros Tahun 2004. Available from: URL: http://ridwanamiruddin. com/2007/05/24/ studi-kasus-kontrol-anemia-ibu-hamil-jurnal-medikaunhas/. (serial online). May, [cited 2011 Feb.5]. 2007.

3. Kusumawati, Yuli dan Mutazalimah. Hubungan pendidikan dan pengetahuan gizi ibu dengan berat bayi lahir di RSUD dr. Moewardi Surakarta. Infokes 8(1); 2004.

4. Depkes RI. Pedoman Pelayanan Antenatal Terpadu. Kementrian Kesehatan Direktorat Jenderal Bina Kesehatan Masyarakat Direktorat Bina Kesehatan Ibu. Jakarta; 2010.

5. Arisman. Buku Ajar Ilmu Gizi dalam Daur Kehidupan. Penerbit Buku Kedokteran EGC. Jakarta; 2004.

6. Hendrayani, Dwi. Proyek lapangan; faktor risiko kejadian anemia di Wilayah Puskesmas II Denpasar Selatan. Universitas Udayana; 2011.

7. Depkes RI. Program penanggulangan anemia gizi pada wanita usia subur (WUS). Direktorat Gizi Masyarakat Dirjen Binkesmas; 2008.

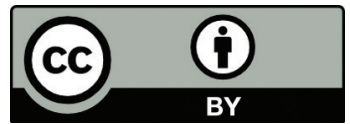

This work is licensed under a Creative Commons Attribution 